\title{
Erratum to: Highlight report: co-cultures of hepatocytes and macrophages for hepatotoxicity testing
}

\author{
Abdel-latif Seddek $^{1}$ - Aya A. Abbas ${ }^{1}$
}

Published online: 6 September 2017

(C) Springer-Verlag GmbH Germany 2017

\section{Erratum to: Arch Toxicol (2017) 91:2963-2964 \\ DOI 10.1007/s00204-017-2019-5}

There is a typo in a reference of this article and it has not been correctly cited. The citation in the published article was:

Hammad S, Abdel-Wareth A, El-Sayed YS (2015) In vitroin vivo correlation: hepatotoxicity testings. JEASS 1(3):384-387.

The correct citation is:

Hammad S, Abdel-Wareth AAA, El-Sayed YS (2015) In vitro-in vivo correlation: hepatotoxicity testings. JEAAS 1(3):384-387.

The online version of the original article can be found under doi:10.1007/s00204-017-2019-5.

Abdel-latif Seddek

abdellatief-shakir@vet.svu.edu.eg

1 Forensic Medicine and Toxicology Department, Faculty of Veterinary Medicine, South Valley University, Qena, Egypt 